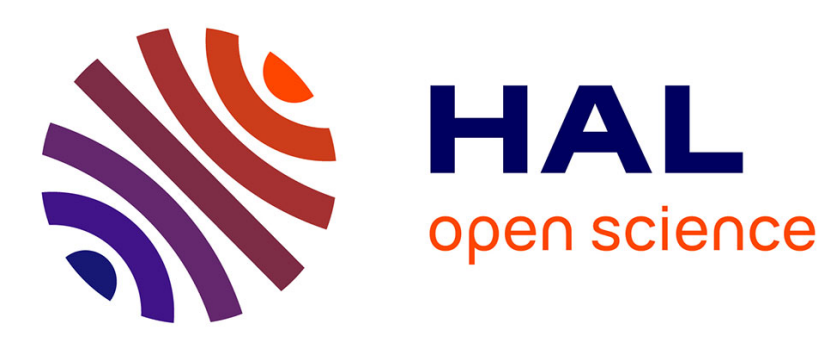

\title{
The High-Performance Cementitious Material (HPCM), a Cousin of UHPFRC for Long-Life Pavement
}

François de Larrard

\section{To cite this version:}

François de Larrard. The High-Performance Cementitious Material (HPCM), a Cousin of UHPFRC for Long-Life Pavement. BFUP, Nov 2009, France. hal-00614032

\section{HAL Id: hal-00614032 \\ https://hal.science/hal-00614032}

Submitted on 8 Aug 2011

HAL is a multi-disciplinary open access archive for the deposit and dissemination of scientific research documents, whether they are published or not. The documents may come from teaching and research institutions in France or abroad, or from public or private research centers.
L'archive ouverte pluridisciplinaire HAL, est destinée au dépôt et à la diffusion de documents scientifiques de niveau recherche, publiés ou non, émanant des établissements d'enseignement et de recherche français ou étrangers, des laboratoires publics ou privés. 


\title{
The High-Performance Cementitious Material (HPCM), a Cousin of UHPFRC for Long-Life Pavement
}

\author{
François de Larrard \\ Senior Researcher \\ LCPC Centre de Nantes, \\ France
}

\begin{abstract}
Summary
Under the framework of OECD/CEMT JTRC, an international team of road research laboratories worked together in order to evaluate technical solutions for long-life pavement. As a matter of fact, there are in many countries highly trafficked road sections where any traffic disruption brings high external costs. For such a case, the aim was to study wearing courses that could last several decades with no maintenance. The paper presents an innovative technical solution, called HPCM (HighPerformance Cementitious Material), consisting of a thin layer of ultra-high performance fibrereinforced mortar with calcined bauxite aggregate embedded in the surface at the fresh state. Many laboratory and two full-scale tests were carried out, dealing with surface resistance (abrasion, wear, shocks, freeze-and-thaw, acid attacks), cracking under restrained shrinkage and fatigue resistance due to heavy traffic loading. New projects were launched recently to continue this coordinated research: a French national project called CLEAN, and an international project called LLPS3. Both of them aim at building circulated road sections to fully validate this promising technology.
\end{abstract}

Keywords: Abrasion resistance, Calcined bauxite, Cracking, Fatigue, Fibres, Freeze-and-thaw, Long-life pavement, Restrained shrinkage, Ultra-high performance concrete

\section{Introduction}

Under the framework of OECD (Organisation for Economic Cooperation and Development), ECMT (European Conference of Ministers of Transport) and their Joint Transport Research Centre (JTRC), a number of road laboratories have worked together to develop the concept of a long-life wearing course for highly trafficked pavements. As a matter of fact, pavements usually consist in base and subbase layers, which last 20-40 years or more, covered by a wearing course having a much shorter life expectancy (typically 7-15 years). However, maintenance works for these surface layers are less and less accepted, and induce high external costs. The first phase of the JTRC-IM3 project (LLP 1) indicated through an economic analysis, that, for some specific applications, it was worth studying technical solutions that could extend the service life for up to 20, 30 or 40 years, with no maintenance nor traffic disruption during this period [1]. In Phase 2 of the project (LLP 2), two technical families were evaluated; a bituminous and a cementitious surfacing. The innovative High-Performance Cementitious Material (HPCM) solution consists of applying an 8-mm layer of ultra-high performance, fibre reinforced fine mortar, in which hard, polish-resistant aggregate particles are embedded [2-5]. The paper gives the results of the HPCM material development. In conclusion, the perspectives opened by this new technology are briefly presented, together with the programme of two recently launched new projects, including the phase 3 . 


\section{Design of the HPCM complex}

One of the most important requirements of a wearing course is the need for good skid resistance, which is dependent upon the aggregate in the surfacing. For a long-life top layer, it is thus necessary to choose an aggregate with a superior polishing resistance. According to general experience, calcined bauxite, an artificial aggregate obtained by subjecting a natural mineral to a thermal treatment, is recognised as one of the best solutions. However, it is an expensive material, with limited suppliers: its unit cost may range from 30 to 40 times that of ordinary aggregates. Therefore, a surface dressing which only comprises a single layer of particles is relevant. Among available aggregate fractions, the $3-7 \mathrm{~mm}$ size has been chosen, because a maximum size of aggregate of around $6 \mathrm{~mm}$ tends to be the optimum size when a combination of adequate skid resistance and limited noise emission is required.

The next requirement is the design of the binder, the key function of which is to stick the calcined bauxite chippings to the pavement. When the option of using a hydraulic binder is taken, one must develop a fine material with the maximum tensile strength obtainable on site. From the experience gained with the ultra-high performance concretes [6-7], a design mix of sand, Portland cement, silica fume, superplasticizer and water, with a low water/binder ratio is suitable. As in the ultra-thin white topping technology [8], a good bond is expected between the cementitious mortar and the bituminous substrate. However, due to the shrinkage of the mortar which will be restrained by the pavement structure, cracking is likely to occur. To limit the crack opening, some sort of reinforcement is needed, but, given the thinness of the mortar layer, only fibres added to the mix are appropriate. The thickness of this fibre-reinforced mortar should be minimal for economic reasons. However, it should prevent the chippings from coming into direct contact with the asphalt layer. Moreover, the chippings/mortar composite should form a strong protecting layer for the lower pavement layers. Thus a thickness of $8 \mathrm{~mm}$ is selected for the mortar. Fig. 1 displays the design of HPCM.

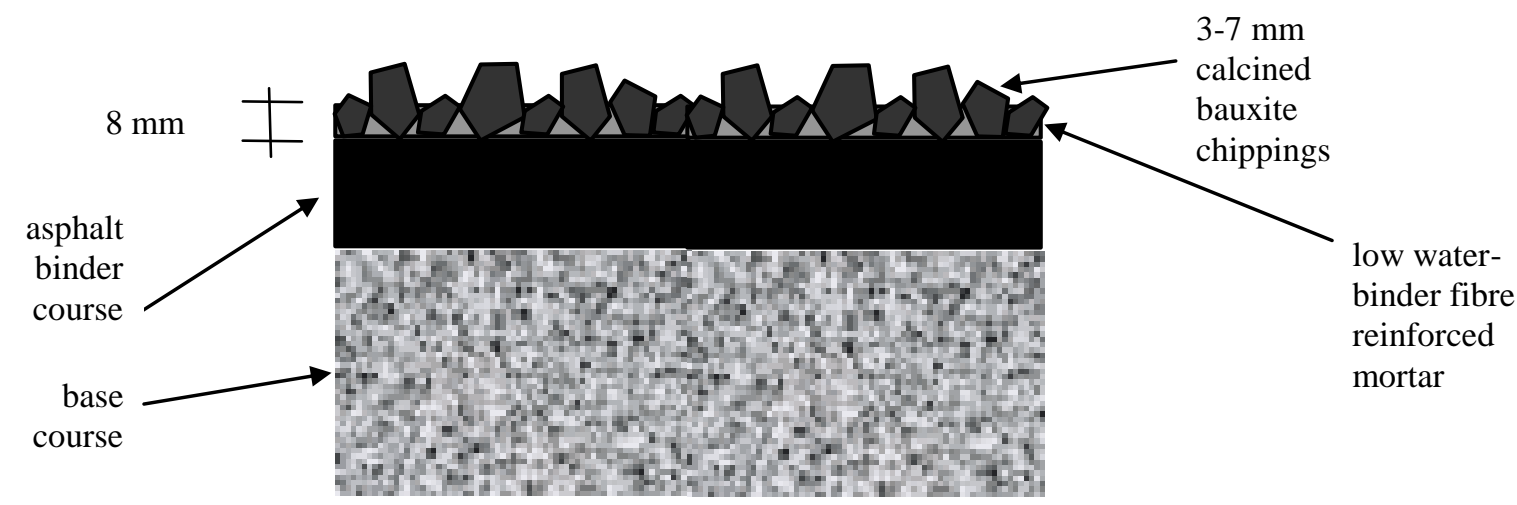

Figure 1. $\quad$ Principle of the HPCM solution [2].

The following constituents were taken for the original mixture designs, based on previous experience of the participating laboratories:

- a 3/7 mm calcined bauxite from China

- an aeolian siliceous fine sand

- a Portland cement CEM I

- a light grey silica fume from Norway

- a polycarboxylate-type superplasticizer in powder form

- steel fibres with a length of $13 \mathrm{~mm}$ and a diameter of $0.2 \mathrm{~mm}$

- alternatively, PVA (polyvinyl alcohol) fibres with a length of $15 \mathrm{~mm}$ and a diameter of 0.33 $\mathrm{mm}$. 
As for the mixture proportions, three ratios were fixed arbitrarily: the water/cement ratio (0.2), the silica-fume/cement ratio (0.2) and the dry superplasticizer/cement ratio (0.003), based on previous experience. As for the fibrous reinforcement, both the type and dosage rate of the fibres had to be determined later, after the results of some specific tests.

A first mortar recipe was developed and tested among the different participants. Later, it was adjusted in order to get a more stable rheological behavior at the fresh state and a better bond, thanks to a softer consistency. Table 1 displays the optimised recipe used in most of the tests performed during the project. This mortar had to incorporate fibres in order to resist to the shrinkage-induced tensile stresses.

Table 1. Mixture-proportions of the plain mortar $C$.

\begin{tabular}{|l|c|}
\hline Components & $\mathrm{kg} / \mathrm{m}^{3}$ \\
\hline Siliceous coarse sand 0.2/1 & 429 \\
\hline Siliceous fine sand 0.08/0.315 & 429 \\
\hline CEM I Portland cement & 985 \\
\hline Silica fume & 197 \\
\hline Superplasticizer (dry powder) & 4.40 \\
\hline Retarder & 4.95 \\
\hline Water & 207 \\
\hline w/c & 0.21 \\
\hline Slump (cm) & 21 \\
\hline
\end{tabular}

\section{Plain mortar tests}

Table 2 displays the main mechanical properties of the mortar, with $4 \%$ PVA fibres. The shrinkage of plain mortar was measured on $7 \times 7 \times 28 \mathrm{~cm}$ specimens, from 1 day up to 250 days. The final autogenous shrinkage was about 650 microstrains, and total shrinkage at $50 \%$ R.H. attained a value of 800 microstrains. Also, the coefficient of thermal expansion was found to be equal to $17.6 \times 10^{-6}$. Therefore, it was verified that this material has the ability to crack in restrained conditions, whatever the outer humidity; fibres are definitely required if cracking is to be avoided.

Table 2. $\quad$ Properties of the hardened mortar $C$ with $4 \%$ of PVA fibres (fresh state properties: slump $23 \mathrm{~cm}$, air content $4.5 \%$ ), after a 28-day curing at $100 \%$ R.H.

\begin{tabular}{|c|c|c|}
\hline $\begin{array}{l}\text { Dimensions of } \\
\text { specimens }(\mathrm{cm})\end{array}$ & Type of test & $\begin{array}{l}\text { Mean value } \\
(\mathrm{MPa})\end{array}$ \\
\hline Prisms $4 \times 4 \times 16$ & Flexural & 28.5 \\
\hline Prisms 4x4x16 & Compressive & 164 \\
\hline Cubes 10x10x10 & Compressive & 148 \\
\hline Cylinders Ø11x22 & E-modulus & 43000 \\
\hline Cylinders Ø11x22 & Compressive & 129 \\
\hline
\end{tabular}

The fiber reinforced mortar was also subjected to up to 25-million of flexural fatigue cycles. With at least $2 \%$ of fibres, it was found that the material could resist, only showing a decrease and a stabilisation of the apparent E-modulus, whatever the nature of the fibres. 


\section{Cracking tests}

The cracking tests were decisive in selecting the type and dosage of fibres. Two campaigns of insitu cracking tests were carried out, where 6-m long, $14-\mathrm{cm}$ wide strips were laid in parallel on an old asphalt pavement (see Fig. 2). After some months, it was tentatively concluded that either $3 \%$ of steel fibres or $4 \%$ of PVA fibres could equally well prevent cracking. The latter solution was preferred, owing to better workability and lower cost induced by these synthetic fibres. A large, $20 \times 2 \mathrm{~m}$ test pad was cast, in order to check that no cracking would appear at full scale. Unfortunately, after a hot early summer, it was found that PVA fibres tended to soften; this reinforcement was then no longer able to overcome the crack development in the strips, unlike steel fibres. Consequently, the final solution recommended by the authors is to use at least $3 \%$ of steel fibres to eliminate any visible cracking. This finding is also confirmed by a series of laboratory cracking tests performed on the mortar phase.

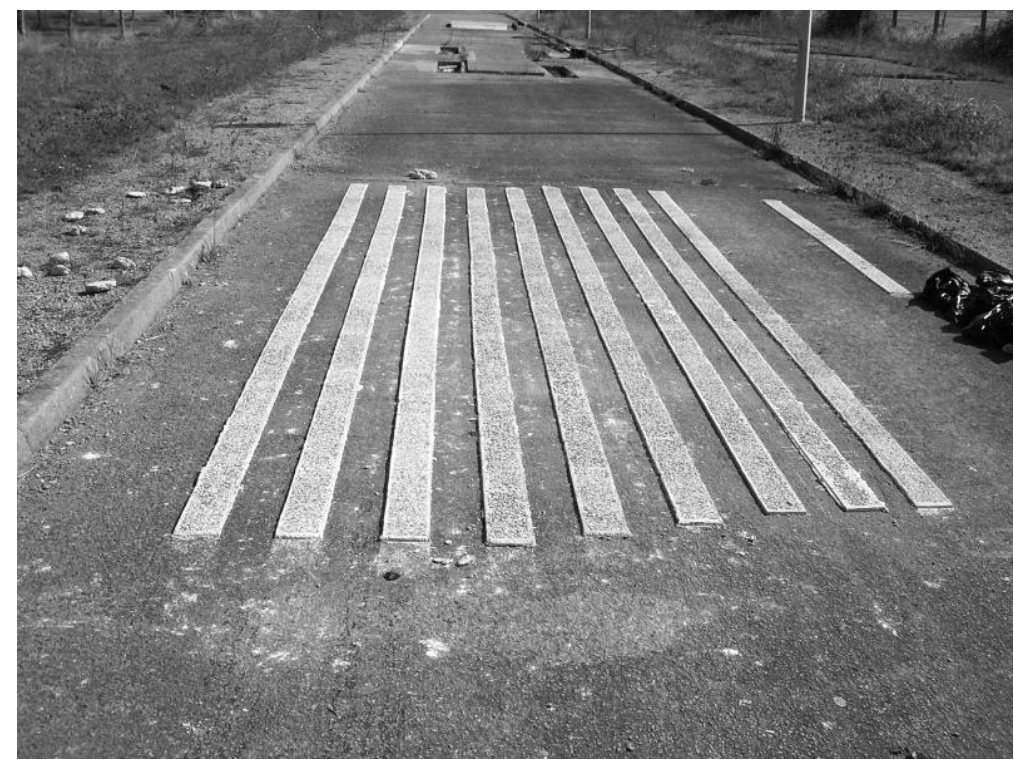

Figure 2. $\quad$ Testing site for the cracking strips (tests performed at LCPC Nantes).

\section{Surface resistance tests}

Various tests were applied on laboratory specimens, in order to investigate the likelihood of surface distress under traffic. Rutting testers, with a cornering angle, resulted in a chipping loss of about $7.5 \%$ in a HPCM specimen, a value that can be compared to $4.5 \%$ obtained with a typical epoxy-asphalt surface dressing. ASTM abrasion tests showed the importance of the embedment process for limiting the amount of chipping loss. A more specific test using a tribometer (see Fig. 3) was then carried out on a series of wearing course materials. At $20^{\circ} \mathrm{C}$, the performance of HPCM was intermediate between conventional bituminous materials and epoxy-asphalt materials (concrete or surface dressing). This result is quite satisfactory, given the fact that the temperature should not affect the HPCM behaviour in the $20-50^{\circ} \mathrm{C}$ range, unlike bituminous materials, whose resistance rapidly drops when the temperature increases. 


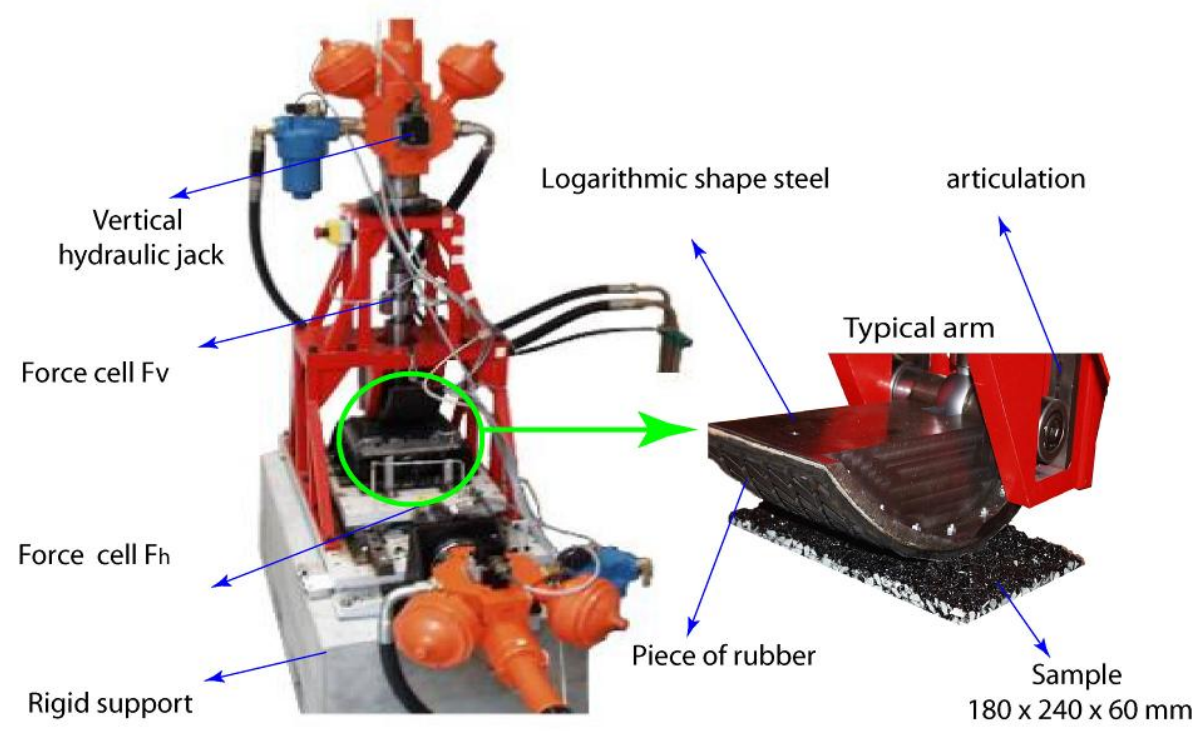

Figure 3. The 'Tribometer'test, recently developed at LCPC (France)

Climatic aggressions were simulated through conventional freeze-and-thaw scaling tests, normally devoted to conventional cement concrete. The results obtained led to classify HPCM behavior in the 'very good' category. Then, a more aggressive test called 'total test', encompassing acid attack, freeze-thaw and shocks was carried out. In the absence of a control material, no HPCM classification can be deduced from this last tests. However, it was found that with up to $20 \%$ of chipping loss, the texture characteristics and skid resistance of HPCM are hardly affected, showing the level of safety that can be attained with such a wearing course material.

\section{Miscellaneous}

The original texture of a cracking strip was acquired and processed through software aiming at simulating the noise generation likely to occur under traffic. It was found that HPCM should behave as an exposed-aggregate cement concrete of similar texture.

Finally, a key performance test was carried out with the TRL Pavement Testing Facility (TRL, see Fig. 4) including an equivalent of $1.0 \mathrm{M}$ standard axles at $20^{\circ} \mathrm{C}$, followed by $0.5 \mathrm{M}$ standard axles at $35^{\circ} \mathrm{C}$. This structural test could help in evaluating a pavement structure with various wearing courses, even if the number of loading cycles remained small with regard to the expected traffic for a long-life pavement.

Three test pads were tested, covered with HPCM, SMA (stone-mastic asphalt) and EA (epoxyasphalt) concrete, respectively. The loading programme at ambient temperature only provoked a slight level of rutting, which greatly amplified when temperature was raised. The HPCM succeeded in limiting the rutting level to $1.5 \mathrm{~mm}$, although much higher values were attained with the epoxy asphalt $(6 \mathrm{~mm})$ and the SMA $(8 \mathrm{~mm})$. The HPCM surface remained sound, with a high skid resistance (SRT value of 92). Some delamination happened at the edges of the HPCM pad in the bituminous base course. This distress was due to the rutting of the base course and the lack of tensile strength at $35^{\circ} \mathrm{C}$. It was therefore concluded that HPCM had to be applied on a quite stiff asphalt concrete, with a low rutting and a low sensitivity to temperature. These requirements are a direct consequence of the search for a long-life pavement, whatever the wearing course could be. 


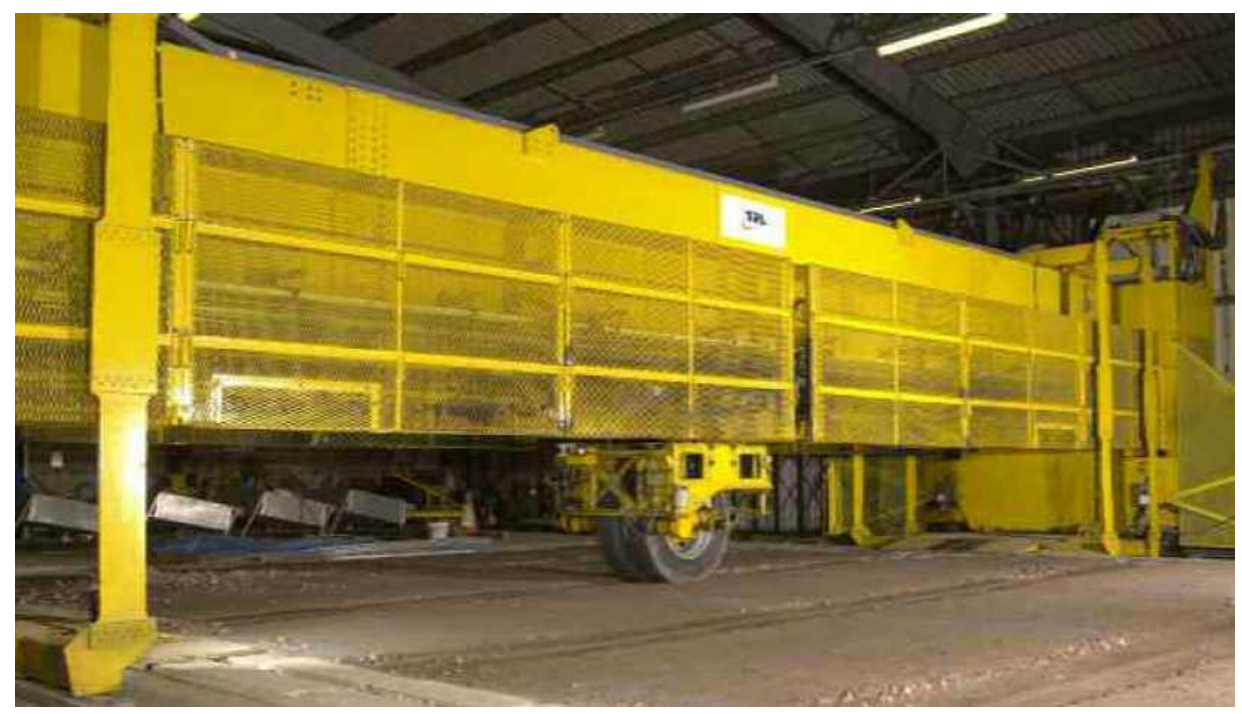

Figure 4. The TRL Pavement Testing Facility (Crowthorne, UK)

\section{The way forward: two new projects to continue the development of HPCM}

After the completion of the OECD/CEMT JTRC 'Long-Life Pavement' project phase 2, most participating countries decided to continue their efforts for practical implementation of long-life pavement technologies. Therefore, the OECD/ITF JTRC 'Long-Life Pavement Surfacings' project phase 3 (LLPS 3) was officially launched in early '2009, coordinated by LCPC. Ten countries will build experimental, circulated test sections using one or both of the materials developed in the previous phase. A common approach regarding the specification, design, control and monitoring of the pavements will be taken as much as possible, and all collected data and experiences will be summarised in a final report. This document shall be a major reference to implement Long-Life Pavement Technology in many countries.

At the French level, a national project was launched at the same time, called CLEAN ('Chaussées à Longévité Environnementale Adhérente et Nettoyante'). The aims are similar to those of LLPS3, but restricted to the hydraulic solution (HPCM). For this material, although much research was performed within LLP 2, it was considered that more research was needed on the production and laying technique, a critical phase for any pavement material. Hence, the requirements are very strict: material quality control, correct bond with base layer, skid-resistance, limited noise generation and superior mechanical durability under high-traffic. CLEAN is gathering eight partners (including road owners, material providers, construction facility builders and research laboratories) with the objective of two successful experimental sites. The first one is scheduled during the fall of 2009, near Le Mans (Sarthe). It is a roundabout, a type of pavement quite appropriate to test a heavy-duty wearing course. For this first site, a semi-mechanised technique will be used to lay the HPCM (see Fig. 5).

The year after, a second construction site will take place in the Loire-Atlantique department, not far from Nantes. A straight street will be covered with HPCM, using a fully mechanised technique. A secondary, depollution function will be added to the material, through the use of titanium dioxide $\left(\mathrm{TiO}_{2}\right)$. Both test sections will be monitored until the end of the project. 


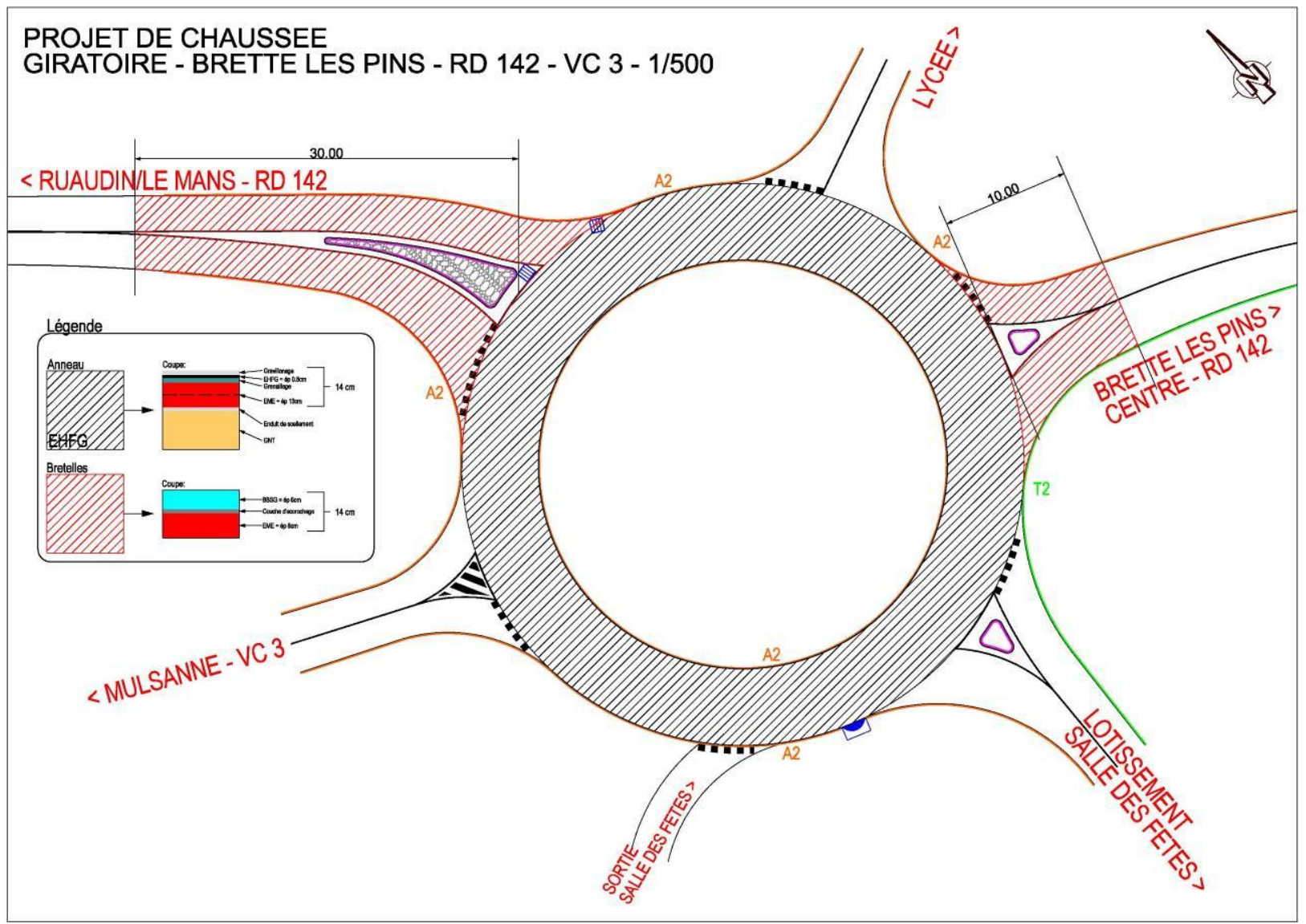

Figure 5. $\quad$ Project of the first HPCM test section in France (in Brette-les-Pins, 72).

\section{Conclusion}

A new material for a long-life wearing course was developed through a large, collaborative scientific project involving thirteen countries, of which seven were active participants. The main idea for the design of HPCM is the use of best quality materials in minimal quantity. The data acquired in the phase 2 program are globally encouraging, and one may expect a much longer lifespan, as compared to current asphalt wearing courses (which last generally between 7 and 15 years). With such a material one may expect 30 to 40 years of mobility without neither maintenance nor traffic disruption. The phase 3 is now engaged, where practical implementations on trafficked test sections will be carried out, supported by the French national project CLEAN. Further development will be necessary during this next phase to develop a suitable construction facility, and to investigate the sensitivity to water dosage and two-dimensional cracking behaviour.

Acknowledgements : the SIKA France company is gratefully acknowledged for the advice in the choice of constituents and the delivery of HPCM premix samples to all participants. 


\section{References}

[1] OECD/ECMT (2004), « Economic evaluation of long-life pavements. Phase I".

[2] DE LARRARD F., GARCIN O., HAMMOUM F., TRAVERS F. (2005), « Preliminary tests on a hydraulic surface dressing for wearing courses with a long life », Technical note, Bulletin des Laboratoires des Ponts et Chaussées, No. 258-259, pp. 121-128, October-December. Freely downloadable at http://www.lcpc.fr

[3] DE LARRARD F., SEDRAN T., CHANDLER J., HENRICHSEN A., SLIWA N., THOEGERSEN F., VOROBIEFF G., YOUTCHEFF J. (2006), "A high-performance cementitious surface dressing for long-life wearing courses", 10th International Symposium on Concrete Roads, Brussels, September 18-22.

[4] OECD/ECMT (2007), « Long-Life Surfaces for Busy Roads - Economic evaluation of longlife pavements. Phase II", OECD 772007031 P1 / ISBN: 978-92-821-0158-2.

[5] DE LARRARD F., CHANDLER J., CHRISTENSEN J., HAMMOUM F., HENRICHSEN A., HIMERIK T., SLIWA N., TANESI J., THOEGERSEN F., VOROBIEFF G., WHITE J., YOUTCHEFF J., "A cementitious long-life wearing course to reduce frequency of maintenance works on high-traffic roads", Transport Research Arena, Ljubljana, April, 2008.

[6] DE LARRARD F., SEDRAN T. (1994), "Optimization of Ultra-High Performance Concrete by Using a Packing Model", Cement and Concrete Research, Vol. 24, No. 6, pp. 997-1009.

[7] RICHARD P. et al. (1995), "Les bétons de poudres réactives (BPR) à ultra-haute résistance (200 à $800 \mathrm{MPa}) "$, Annales de l'ITBTP, No 532, pp. 81-143, Mars-Avril.

[8] RASMUSSEN R. O., ROZYCKI D. K. et al. (2004), « Thin and Ultra-Thin Whitetopping - A Synthesis of Highway Practice", NCHRP synthesis 338, TRB, Washington, 96 p. 